\title{
Bodily sensations and the varieties of spatial bodily awareness
}

\author{
Sensaciones corporales y las variedades de conciencia de la corporalidad \\ espacial \\ Luis Alejandro Murillo Lara* \\ Universitaria Agustiniana, Bogotá, Colombia. luis.murillo@uniagustiniana.edu.co
}

Recibido El 30 de NOVIEMBRE DE 2020, APROBAdo EL 17 DE DICIEMBRE 2020

\begin{abstract}
This paper addresses the question of whether awareness of the spatial properties of our body is achieved through bodily sensations. We begin by analyzing our current understanding of the spatial dimension of bodily sensations. The notion of non-observational knowledge is introduced as the main objection to the idea that bodily sensations are the means by which we are aware of any spatial property of our body. We discuss two important philosophical criticisms of such a notion, as well as a series of empirical findings that could be interpreted as objections. We finish by considering an alternative explanation of our awareness of the spatial properties of our body.
\end{abstract}

\section{KeYwORDS}

Bodily sensation; bodily awareness; spatial awareness; non-observational knowledge.

\section{RESUMEN}

Este artículo aborda la pregunta de si la conciencia de propiedades espaciales de nuestro cuerpo es obtenida mediante sensaciones corporales. Empezamos analizando nuestra comprensión actual de la dimensión espacial de las sensaciones corporales. Luego introducimos la noción de conocimiento no-observaciones como principal objeción a la idea de que las sensaciones corporales son el medio por el cual somos conscientes de cualesquiera propiedades espaciales de nuestro cuerpo. Enseguida presentamos dos importantes críticas filosóficas a dicha noción, así como una serie de hallazgos empíricos que podrían interpretarse como objeciones al conocimiento no-observacional. Terminamos considerando una explicación alternativa a nuestra conciencia de propiedades especiales de nuestro cuerpo.

\section{Palabras clave}

Sensaciones corporales; conciencia corporal; conciencia espacial; conocimiento no-observacional.

\footnotetext{
* (1) orcid.org/0000-0002-8156-4128 Google Scholar
} 


\section{Introduction:}

\section{Our Immediate Awareness of Spatial Aspects of Our Body}

In everyday life, we are immediately aware of a variety of spatial details about our body. If we are outdoors during severe winter, we can tell which specific parts of our body feel cold (e.g., face, ears, and hands). It also happens if we are bitten by a mosquito: not only do we feel the characteristic itch, but we are able to tell the itching place. We know whether our limbs are stretched or bent, and not just because of tactile stimuli over the skin of the relevant limb, since we would know this even if we were swimming underwater, where tactile stimuli are often undifferentiated. By the same token, we know whether we are standing or lying down, as well as whether our limbs are moving. Location, motion, and posture are some of the spatial attributes of our body that we become aware of, and we are immediately informed about them, even though we are not aware of them first by means of the familiar senses or through the exercise of our inferential capacities (O'Shaughnessy, The Will, 171).

The literature addressing our awareness of spatial aspects of our body has focused on bodily sensation (Armstrong, Bodily sensations; Bermúdez, The paradox of self-consciousness; de Vignemont, "Bodily spatial content"; De Vignemont, Mind the body; Margolis, "Awareness of sensations and of the location of sensations"; Merleau-Ponty, Phénoménologie de la perception; O'Shaughnessy, The will; Vesey, "The location of bodily sensations"; Vesey, "Bodily sensations").- This seems to be due to the (sometimes implicit) assumption that such an awareness is achieved through bodily sensations (I will call this thought 'the primacy claim'). O'Shaughnessy explicitly endorses a version of the primacy claim (that our awareness of the other spatial aspects derives somehow from our awareness of the location of bodily sensations) when he states that "limb posture joins 'feel' (...) as elements of the 'given'" (The Will, 236), and that 'bodily sensations cause an awareness of themselves as set in a specific position in a determinately postured limb, and simultaneously those same sensations cause awareness of the very limb in which they themselves come as seemingly set' (The Will, 236). Even empirical research on the subject seems to make that assumption (Proske \& Gandevia, 1651; Longo \& Haggard, 11728).

The main goal of this paper is to call the primacy claim into question, and to outline an alternative understanding of our awareness of 
the spatial properties of our body-according to which some of that awareness might be rather 'non-sensory'. To that end, we begin by focusing on our understanding of the spatial dimension of bodily sensations, and to explore whether it provides support for the primacy claim. We then introduce a notion that constitutes both an objection to the primacy claim and the bedrock of a potential contender for explaining our immediate awareness of the spatial properties of our body, namely Anscombe's notion of non-observational knowledge. Next, we discuss some major objections to the aforementioned notion, which purport to prove it conceptually flawed. We go on to address another possible objection, this time coming from empirical findings in the field of neurophysiology (where it is common to hear about 'sensations of limb position' and 'sensations of limb movement'). Our conclusion will be that the proposed view surmounts those objections, and could thus offer an alternative explanation of our grasp of the spatiality of our body.

\section{Support for the primacy claim?}

A first problem with endorsing the primacy claim is that it presents awareness of bodily sensations as explanatory of awareness of any spatial aspect of our bodies, as if the nature of the former were sufficiently clear to see the way it entails the latter. There is indeed a certain consensus in that, together with their intrinsic qualitative aspect, bodily sensations bring with them a spatial element that refers mostly to their relative bodily location (Martin, "Sense modalities and spatial properties"; O'Shaughnessy, The Will; Bermúdez, The Paradox of Self-Consciousness). However, does our best understanding of the spatial dimension of bodily sensations shed light on our awareness of other spatial aspects of our body? In this section we will try to briefly reconstruct the path that leads to the most promising conception of the spatiality of bodily sensations, and look at whether it somehow leads to the primacy claim.

Over the decades, neurophysiological research has gathered evidence pointing to the fact that bodily sensations are not literally located in the body parts in which they are felt (for example, Penfield \& Jasper, Epilepsy and the functional anatomy of the human brain). Yet it is their felt location that we usually call 'the location of a bodily sensation.' The problem, then, has been to explain what makes a bodily sensation to be felt where its subject feels it -in other words, to define what we mean by 'the felt location of bodily sensations.' 
The following thought is very tempting: when something happens in a part of my body, it causes a sensation that I experience as being in that body part, so the felt location of a bodily sensation could be simply defined as the place of its cause. The fact that some physical events on certain body parts may cause bodily sensations that are felt somewhere else, however, (Schaefer, Noennig, Heinze, \& Rotte, "Fooling your feelings"; called by O'Shaugnessy, The Will, 221, referred sensations) prevents us from claiming that the felt location of a bodily sensation is the place of its cause.

O'Shaughnessy and Armstrong discarded other attempts at a definition of the felt location of bodily sensations:

-The place where we believe the cause of the sensation to be (we could have a known referred sensation).

-The place we are inclined to believe the cause of the sensation to be (the acquisition of such an inclination remains unexplained).

-The place in objective physical space occupied by the body part in which the sensation is (the place of a sensation cannot be a position regardless of subjects or 'relative to the fixed stars', The Will, 222).

-The place in the biological body where the sensation seems to be (think of phantom limb sensations).

So, the conceptual space available for the desired definition excludes simple causal definitions, 'doxastic' definitions, and those involving physical space or bare anatomical considerations.

One reaction could be to reject the problem altogether, and claim (as Lotze, Microcosmus) that bodily sensations do not have an inherent spatial component and that they are individuated exclusively by qualitative aspects. The qualitative aspect of bodily sensations could be said to depend on the body part, and, as a result, we come to associate those qualitative aspects with specific bodily locations. However, it is a plain fact that qualitatively indistinguishable sensations can be felt in different locations. Denying an intrinsic spatial location for bodily sensations also commits one to accepting 'a-spatial' or 'freefloating' bodily sensations, of which we lack any sound example (De Vignemont, Mind the body, 68).

An option that seems to lie within the available conceptual space is the claim that awareness of bodily sensations and their location would be constituted by knowledge of, for example, how to get to the location of the stimulation (Noë, Action in perception; Noë and 
O'Regan, "A sensorimotor account"; Hurley, Consciousness in action). Nevertheless, bodily illusions such as the Rubber Hand Illusion (Botvinick \& Cohen, "Rubber hands 'feel' touch that eyes see") have been used to show that the spatiality of bodily experiences can be at odds with bodily know-how, inasmuch as rapid reaching movements toward the stimulated hand remain accurate in spite of the spatial illusion (see de Vignemont, Mind the body, 77). Moreover, we can also find awareness of bodily sensations without bodily know-how, as in patient KE (Anema et al., "A double dissociation”). ${ }^{1}$

Finally, it has been posited that by virtue of a causal connection between an abiding neural structure and bodily locations, when stimuli are received in some body part, that neural structure causes a sensation to be felt in a specific body point (O'Shaughnessy, The Will; O'Shaughnessy, "Proprioception and the body image"; de Vignemont, Mind the body). By making that structure (a body representation) a necessary condition for bodily sensations to have a spatial component, this approach goes beyond simple causal definitions. Furthermore, in addition to inheriting the advantages of representationalism to account for error and illusion, it acknowledges the intrinsic spatiality of bodily sensations and does not make any claims as to the connection between action and such spatial aspects.

This latter representationalist account appears to stand out among other explanations of the spatial dimension of bodily sensations. Nonetheless, it is hard to see what it is in that view which could possibly entail that our awareness of all spatial aspects of our body comes from bodily sensations (viz., our awareness of their spatial dimension). So, despite providing us with a better understanding of the spatial component of bodily sensations, as such, representationalism does not imply that any spatial awareness of our body is gained through bodily sensations.

\footnotetext{
${ }^{1}$ Yet, see Mandrigin ("The where of bodily awareness") for a defense of the view that the spatiality of bodily awareness comes from connections between somatosensory input and motor output. According to her view, the empirical evidence for dissociation is consistent with the recalibration of visual and motor reference frames. We think that her proposal deals with cases in which (unlike those she addresses) visual and motor reference frames seem to be used in a synchronous rather than diachronic manner - as in the rubber hand illusion. That seems hard to explain in terms of a single reference frame, because if the same frame is being used for both the visual and the motor tasks, why do we have conflicting visual and motor judgments? (For additional reasons for the postulation of separate body representations, see de Vignemont, "Body schema and body image" $)$.
} 


\section{Against the primacy claim: non-observational knowledge}

A second, more critical problem for the primacy claim comes from arguments against it. The most prominent case against the primacy claim, and for the view that our immediate knowledge or awareness of limb position and limb motion would not come from sensations, can be found in the works of Anscombe. ${ }^{2}$ Her view (Intention, 13) is that we can say we know something 'by observation' when we have a separable sensation we use as a criterion to assert it-and in turn, a sensation is separable when it can happen independently from the object or the situation we use to describe it. In other words, something characteristic of our sensuous awareness is that the sensations by means of which we know things are somehow independent of the particular object or situation they allow us to know. For instance, I know I was sunburnt by means of a characteristic sensation on my skin, but I can also feel that sensation without being sunburnt-such as when I have some allergic skin reaction.

Sensations of limb position (or limb motion), however, do not seem to have that independence from the objects or situations they allow us to know - they would not be separable, in Anscombe's terms ("On sensations of position", 55). Rather, those sensations seem to be somehow 'transparent': when I try to remember the sensation by means of which I knew my arm was bent, I cannot separate it from the very situation of my arm being bent. If asked to imagine the sensation, what we imagine is the object or situation we allegedly know through the so-called sensation. Following Anscombe, when we cannot find a separable sensation, we have no reason to say that we know an object (or situation) by means of sensations ('by observation'). Anscombe grants that we know the posture of our body and limbs, because we can be right or wrong about it (Intention, 14); what she casts doubt upon is that we can justify the claim that this is observational knowledge-or even that there are such sensations of limb position. If so, that knowledge would be non-observational.

A possible response is that, despite not being describable in isolation from the object or situation, they allow us to know, sensations of

\footnotetext{
${ }^{2}$ Knowledge of limb position comprises a tiny part of Anscombe's (Intention) endeavor of characterizing intentional action. She claims that knowledge of our own actions is nonobservational, and it is as an illustration of something other than intentional action that is also known without observation, that limb position enters the scene.
} 
position still constitute some kind of ineliminable phenomenological data. Yet, what is needed is not just a simple affirmative answer to the question 'how does it feel to have one's arm bent?', but a non-trivial answer to the question 'how does it feel to have one's arm bent?' Anscombe's argument is that if we cannot do the latter, we are not allowed to do the former either.

Anscombe conceded that 'it may be because one has sensations' that one can know limb position (Intention, 49; see also "On sensations of position", 58), however she argued that even if it was because we have them that we are able to know our bodily posture, it does not follow that we know our posture through them. They might be a requirement for awareness of bodily posture, not the means by which we know it (that would be why a person with an anesthetized limb cannot tell what position that limb is in). Her argument is then that even if sensations were causally necessary for this knowledge, it does not follow that sensations are epistemologically relevant to it.

If the immediate knowledge we have of our bodily posture and bodily movements does not come from sensations, how is it obtained? It may seem that a non-observational knowledge is a kind of 'mysterious acquaintance' (Jones, "Things known without observation"), however, as McDowell (138) has pointed out, Anscombe seemed to have in mind a fallible capacity to immediately know things that is not sensory. Perhaps some neurophysiological phenomena would be able to directly cause this kind of awareness - a non-sensory ability to be immediately aware of things, and which may err. Perceptual capacities would thus be one subset of (and not equivalent to) capacities for non-inferential knowledge. ${ }^{3}$

Now, think again of the swimming example at the beginning of this paper. If we used it to put pressure on the question of how someone knows the posture of their limbs, they could well answer 'I don't know, I simply know it.' That kind of answer would speak in favor of the claim that we can think of such awareness without also thinking of

\footnotetext{
${ }^{3} \mathrm{O}^{\prime}$ Shaughnessy was utterly aware of the possibility that McDowell describes. At the beginning of his seminal paper "Proprioception and the Body Image", he asked: "Might it perhaps be that we are misdescribing as a perceiving or noticing what is in fact no more than an immediate knowledge of limb presence and posture, caused let us say by either cerebral events or postural sensations produced by limb posture? Why posit an intervening event of perception?" (175). His answer-roughly, that bodily awareness is recessive (182) - , however, does not address Anscombe's separability argument.
} 
some related sensation. Although we cannot think of our knowledge of some spatial facts about our body, but through thinking of sensations, we seem able to think about our awareness of spatial properties of our body without also thinking of some related sensations. What happens with our knowledge of limb position would thus be unlike what happens when I know where it hurts; it is not that 'I simply know it' but that I know it because it hurts there.

\section{Against Non-Observational Knowledge}

Anscombe's notion of non-observational knowledge has been widely discussed, and particularly her claim that both knowledge of bodily posture and our own actions are non-observational (Intention, 13, 49). It has been contended, for example, that - as every other form of knowledge-one's knowledge of one's actions must exhibit features as sensitivity to evidence. It is thus claimed that this condition can only be met if one's knowledge of one's actions is somehow observational (Pickard 205).

According to Pickard, in order for one's knowledge of one's actions to be thoroughly sensitive to new evidence, it has to be sustained over the period of time during which the action takes place. In other words, the subject must be somehow sensitive to the course of their own actions through time. Moreover, Pickard adds, the fact that one's knowledge of one's actions keeps pace with one's actions supports the claim that it is present-tensed. On this basis, she criticizes some accounts according to which one's knowledge of one's actions represents that one will do something as true (and it is thus sensitive to evidence as to what one will do; Velleman, Practical reflection, Setiya, "Practical knowledge") on the grounds that it only explains our knowledge of our (immediately) future actions. As does Anscombe, Pickard also discards any account positing that one can only know what one is actually doing if one can independently establish that the result one intended occurred. In Pickard's view, that account would only explain what one just did.

At the heart of Pickard's approach to the knowledge of action is her view of bodily awareness - thence the relevance of her approach to our discussion. She claims that it is proprioceptive bodily awareness that allows one to sustain one's present-tensed knowledge that one is acting over the course of the action, insofar as it is a recessive and continuous form of perception of our own bodies 'from the inside' that provides 
one with awareness of its current position and of (being now) acting with it. That role of bodily awareness would entitle one to say, she declares, that it is somehow necessary to appeal to observation (through proprioception) to explain how one's knowledge of what one is doing is sustained over the period of time in which one is doing it.

Pickard grants the Anscombian claim that the awareness of the current position of one's body provided by proprioceptive bodily awareness is not based on any particular sensations (216). Further, she takes that as not implying that one's grasp of one's limb position is not based on the perception of one's limb position. How can it be? One possibility is that she is thinking of awareness of limb position as a sort of non-sensory form of perception - very similar to the view that we have been ascribing to Anscombe. As we pointed out, however, when Anscombe speaks of 'knowledge without observation' she is thinking of a non-sensation-based form of knowledge, so when Pickard concludes that knowledge of action is observational because of the role of proprioception in making us aware of the position of our limbs, she is either using the expression 'observation' differently than Anscombe, or else she is overlooking the non-observational character of awareness of limb position.

Another possibility is that Pickard indeed sees awareness of limb position as a form of sensory perception, because what she actually says is that such awareness is not based on any particular sensation - rather than not based on any sensations whatsoever. Awareness of one's limb position could still be drawn from other sensations, for instance from those that one has in the relevant limb. Unfortunately, it is hard to see how that alternative could avoid falling into an inferential view of the knowledge of limb position that we have rejected.

On the other hand, there is the issue of bodily awareness as providing awareness 'of [being now] acting'. Pickard does not provide crucial information in that regard, which makes her suggestion hard to assess, or information about the relation between awareness 'of [being now] acting' and awareness of limb position: is the former dependent on the latter? If so, is the former sensory or non-sensory? If both are sensory, what would the sensory difference be between the bodily awareness of one's arm rising and the bodily awareness of one raising one's arm? 
Finally, in discussing whether observing oneself acting would imply the alienation of one's actions, Pickard replies that there is no alienation because what one is doing is not discovered by observation. Given the above, it is unclear whether Pickard means that one discovers what one is doing without sensations or without perception, or her explanation of how we discover it. In any event, she adds that 'observation need not inform one of what one is doing, but only of when one is doing it' (228). By the end of her paper, she makes a further comment regarding deafferentation (in which there seems to be knowledge of one's actions in the absence of bodily awareness), namely, that her account applies 'for most of us, most of the time' (229).

In summary, Pickard's proposal would be that a non-sensory form of the perception of the position of our limbs - which we ordinarily (although not necessarily) have-allows us to have knowledge of the time course of our ongoing actions. To that extent, instead of pointing in a direction different from Anscombe's, Pickard seems rather to have elaborated on it.

Before finishing, it is also worth mentioning one of the earliest criticisms of Anscombe's notion of knowledge by observation. According to Vesey, even the use of the word 'observation' is misguiding because it 'readily lends itself to very many things, with which Miss Anscombe is not concerned at all' ("Knowledge without observation", 205). One of his main targets was the claim that we cannot speak of knowing something 'by observation' unless we can single out separately describable sensations. Vesey questioned whether Anscombe could plausibly analyze the case of seeing something red, since either there are separately describable sensations involved or there are not. The former option would require describing the sensation of seeing red separately from seeing a red thing, whereas the latter would imply that it is not observational knowledge.

Despite the prima facie force of Vesey's argument, the former option might be misleading. Perhaps what is required in order to have separately describable sensations in that case is to describe the visual sensation separately from seeing particular red things-after all, mutatis mutandis, the requirement would not be met in the visual case when the description of the sensation is identical to the description of the particular object seen. The sensation would thus be separately 
describable if one can have it without seeing, say, ripe tomatoes (for example, if one can also have it when one sees some apples). ${ }^{4}$

The results of our discussion about two prominent criticisms of the notion of non-observational knowledge can be summarized as follows: while Pickard does not seem to succeed in establishing that observational knowledge is necessary for our knowledge of our actions - her argument, indeed, seems to admit the non-observational character of the proprioceptive awareness of limb position involved in one's actions - , Vesey's reading of the separability criterion would not take into account the particular scope that Anscombe gives to it. The path is still not clear for the notion of non-observational knowledge, however, since there are potential threats not only on conceptual grounds; some empirical considerations appear to go against it. Those considerations, which we will address in what follows, would lead us beyond philosophical disbelief and might constitute evidence against the notion of non-observational knowledge.

\section{Anscombe versus physiology?}

There is a vast and well-established literature in physiology that seems to directly contradict Anscombe's thesis that awareness of limb position and movement is non-observational. Researchers in this literature begin by pointing out that in our daily lives we depend on signals about our bodies coming from proprioception and other modalities to perform our everyday activities (Proske \& Gandevia 1651; Longo \& Haggard 11727), and that we know where our limbs are even when we are not moving them or looking at them and they lie relaxed (Sherrington, "The muscular sense").

Awareness of limb position and movement is said to be provided by signals of muscle and joint flexion or extension (Sherrington, The integrative action; Burgess, Wei, Clark, \&Simon, "Signaling of kinesthetic information") that arise from receptors in muscles, joints, and skin, whose afferences project to the cerebral cortex (McIntyre, "Central actions of impulses"). Muscle spindles would be the main receptors signaling limb position and movement: for instance, awareness of limb position and movement persists immediately after joint replacement, in

\footnotetext{
${ }^{4}$ Presumably, visual sensations of red form a kind, having therefore something in common despite differences between shades or hues.
} 
which muscle spindles remain intact (Grigg, Finerman, \& Riley, “Jointposition sense after total hip replacement"); similarly, the illusion of limb movement and displaced position produced by vibration over the tendon or muscle has been found to be largely caused by the activation of the primary endings of muscle spindles (Goodwin, McCloskey, Matthews, "The contribution of muscle afferents"). Similarly, the reduced awareness of movement in elderly human subjects seems to be the result of the degraded responsiveness of muscle spindles. Even though the brain can receive some information about the position and movement of a joint from joint receptors and skin stretch receptors (slowly adapting type II), the signaling capacity of the former seems rather limited and skin input can be ambiguous (Macefield, Gandevia, \& Burke, "Perceptual responses to microstimulation"). In the case of the more proximal joints (e.g. those in the legs), joint and skin receptors do not play a significant role in the awareness of limb position and movement-even more, movement detection thresholds of skin afferents for proximal joints are lower than for more distal joints. ${ }^{5}$ It has thus been proposed that limb movement would be signaled by the response to the change in muscle length of the primary ending of muscle spindles, while the mean rate of background discharge in muscle spindles might signal limb position (Proske \& Gandevia 1658).

It has also been found that several factors may affect awareness of limb position. There is muscle thixotropy, for instance, by which previous movements change spindle sensitivity, producing changes in perceived limb position (Gregory, Morgan, \& Proske, "Aftereffects in the responses of cat muscle spindles"). Likewise, the effort required to move a limb influences limb position awareness. For example, it has been reported that position errors may arise from the combined effects of load and movement (Jones, "Motor illusions"); whereas pain leads to overestimation of effort (subjects think painful arms generate more force than they actually did; see Weerakkody et al., "Force matching at the elbow joint"). A method extensively used to alter the perceived effort to move a limb-eo ipso affecting awareness of limb positionuses muscular fatigue derived from exercise (Jones \& Hunter, "Effect of fatigue on force sensation"; Carson, Riek, \& Shahbazpour, "Central and peripheral mediation"): as there is loss of force due to metabolic factors, moving fatigued limbs requires more effort, and the discharge

\footnotetext{
${ }^{5}$ Anyway, as Proske and Gandevia point out (1659), contributions from all those receptors seem to be required for full proprioceptive acuity.
} 
rate of the muscle spindles increases; the brain, in turn, interprets this increase as a more stretched muscle, leading to a shift in perceived limb position (note also that awareness of limb movement decreases with fatigue from exercise; see Pedersen et al., "Localized muscle fatigue"). A subject with fatigued limb muscles may thus be less sure of where their limbs are unless they look at them (Proske \& Gandevia 1677).

In a similar vein, Jones, Cressman, and Henriques (373) have provided evidence that awareness of limb position is not completely accurate 'by default', at least when it comes to one's hands. In their experiment, subjects misperceived the position at which their hand was aligned with a reference marker. Participants judged their right hand to be further rightwards than it was, and their left hand to be further leftwards than it was-with reaching biases similar in magnitude despite being opposite in direction.

It is beyond dispute that we receive information about limb position and movement from receptors in the muscles and joints, and have a continuous awareness of where our limbs are and whether they are moving. The question is whether those proprioceptive signals are (or lead to) sensations of limb position and limb movement, that is, whether there is a sense of limb position and movement. Most of the aforementioned empirical literature concedes that it is so, and the reasoning seems to be something like the following: there must be sensations, after all we have a form of awareness which involves signals from dedicated receptors projecting to the cerebral cortex (see, Proske \& Gandevia 1651). The claim is made despite it also being acknowledged that proprioceptive signals 'are not associated with specific, recognizable sensations' (1652; see also Cullen, "Sensory signals"). So, what sensations are we talking about then? About sensations that must exist (since dedicated receptors project to the cortex) but that cannot be identified.

Rather than having established that there are sensations of position, the neurophysiological literature has thus appealed to a kind of abductive reasoning (that may well fall prey to the Anscombian separability argument). ${ }^{6}$ Indeed, there might be a way to make those neurophysiological findings compatible with Anscombe's criticism of sensations of position.

\footnotetext{
${ }^{6}$ Alternatively, the use of the expression "sense of limb position" in the neurophysiological literature might be looser, namely, one that does not imply associated sensations. If so, the use of the expression "sense of" would be misguiding, probably reducible to "awareness of".
} 
Attempting to account for the lack of identifiable sensations, Proske and Gandevia (1652) note a 'general concept in sensory physiology' according to which, if there is no mismatch between the expected reafference of a movement and that actually generated, then no definable sensation is produced yet the subject knows the location of their limbs. Voluntary motor activity affects the generation of peripheral signals (we are aware of muscle contractions accompanying the action), but not all of the reafferent information reaches consciousness. It has been posited (see Cullen, "Sensory signals"; Bays \& Wolpert, "Computational principles") that when the ongoing reafferences match those predicted (thanks to the 'efference copy'), a cancellation signal is sent to the vestibular-only cells, thereby diminishing their activation through reafferent input and allowing passage to the cortex of only the exafferent component. That is why there is no accompanying sensation.

This would explain why, despite receptors projecting to the cortex, their activity does not lead to sensation - at least in the case of active proprioception, and at least in the case in which reafference and efference copy match. Furthermore, since even in that case we are aware of the position of our limbs and of some muscle contractions accompanying our actions, some reafferent information must be allowed passage to the cortex - just not so that it leads to sensation (which, in turn, would imply that not all of this information leads to sensation even when it reaches the cortex and leads to a form of awareness). It remains to be seen whether something similar can be said to happen in passive proprioception and in cases of mismatch between the reafference and the efference copy (the point still being that in those situations we lack 'identifiable' or 'definable' sensations of limb position and movement).

\section{Aftermath}

Let us sum up the results of our discussion so far. After describing what we called the 'primacy claim', we first argued that it lacks a solid support in our understanding of bodily sensations. In this vein, we introduced a direct counterargument to the primacy claim, which might also support a competing explanation for our awareness of some spatial properties of our body: the notion of non-observational knowledge. We then discussed some philosophical criticisms of the notion of nonobservational knowledge, which we found uncompelling, and some empirical work that seemed to go against such a notion. In regard 
to this latter, our view is that the empirical evidence is compatible with the notion of non-observational knowledge. Consequently, the strength of the primacy claim would end up being at most intuitive, and there would seem to be good reason to think that the notion of non-observational knowledge provides the bedrock for an alternative candidate to the conception posited by the primacy claim to explain our awareness of the spatial properties of our body.

Two points are worth keeping in mind at this stage. The first is that one important difference between the two forms of non-observational knowledge that Anscombe discussed-that of one's actions and that of limb position and movement-might explain why the nonobservational character of the latter seems so hard to concede. If it is equated to knowledge of one's intentions, even defenders of what I have called 'the primacy claim' would be willing to admit that knowledge of one's actions is not perceptual. O'Shaughnessy, for example, granted that 'my knowledge of the impending act is immediate' (The Will, 129) and that it 'is not to be explained through appeal to evidential considerations' (134). To that extent, we have a non-sensory source of the knowledge of one's actions (or at least part of it, namely, knowledge of one's intention); but Anscombe does not provide anything of the kind in the case of awareness of limb position and movement. It is thus important to posit as the source of awareness of limb position a fallible non-sensory capacity to be immediately aware of spatial properties of one's body, a capacity that appears consistent with neurophysiological findings.

Secondly, it is worth keeping this kind of awareness apart from other forms of knowledge that have been described. To the extent that both are direct, unmediated forms of awareness, Anscombe's non-observational knowledge may appear similar to knowledge by acquaintance (Russell 78). Whereas for Anscombe there is nothing sensory in non-observational knowledge, however, at least for Russell (32) what we know by acquaintance is sense data. Similarly, inasmuch as Anscombe sees non-observational knowledge of one's actions as practical or directive - it is 'the cause of what it understands' (Intention 56 and 87) - , someone could be tempted to see a connection to claims about the knowledge of one's body and action as procedural (i.e., knowledge that is manifested in the use of skills). Unlike the way procedural knowledge is usually seen (Devitt, "Methodology and the nature of knowing how"), however, for Anscombe non-observational 
knowledge plays an important role in enabling us to make certain judgements (Intention, 13) whereby the connection with procedural knowledge would be, at best, partial.

Finally, if awareness of some spatial aspects of our body can be gained without sensations, two types of spatial bodily awareness should be distinguished: on one hand, our awareness of the location of bodily sensations, and, on the other hand, our awareness of limb position, motion, and perhaps other spatial properties - the former, but not the latter, requiring bodily sensations. ${ }^{7}$

Some questions remain for further research, especially with the aim of articulating the outlined alternative conception: What is the relationship between these two types of awareness of spatial aspects of our body? Since it is known that perception may affect our awareness of the location of bodily sensations (Botvinick \& Cohen, "Rubber hands"), how does perceptual information interact with awareness of limb position? Enhancing our comprehension of the relationship between the forms of awareness of spatial aspects of our body, and between those forms and perception, are no doubt the next steps in this subject.

\section{REFERENCES}

Anema,Helen A., etal." Adouble dissociation between somatosensory processing for perception and action." Neuropsychologia 47.6 (2009): 1615-1620.https:/ / doi.org/10.1016/j.neuropsychologia.2008.11.001

Anscombe, Gertrude Elizabeth Margaret. Intention. Harvard University Press, 1957.

. “On sensations of position." Analysis 22.3 (1962): 55-58. https://www.jstor.org/stable/3326426

Armstrong, David Malet. Bodily sensations. Routledge, 1962.

Bays, Paul M., and Daniel M. Wolpert. "Computational principles of sensorimotor control that minimize uncertainty and variability." The

\footnotetext{
${ }^{7}$ Now, even if other theorists may claim that their views differentiate awareness of a sensation's location from that of limb position and similar properties, what is at issue is the basis on which the distinction is made, i.e., the way those forms of awareness are conceived.
} 
Journal of physiology 578.2 (2007): 387-396. https:/ / doi.org/10.1113/ jphysiol.2006.120121

Bermúdez, José Luis. The paradox of self-consciousness. MIT Press, 1998.

Botvinick, Matthew, and Jonathan Cohen. "Rubber hands 'feel' touch that eyes see." Nature 391.6669 (1998): 756. https://doi. org/10.1038/35784

Burgess, P. R., et al. "Signaling of kinesthetic information by peripheral sensory receptors." Annual review of neuroscience 5.1 (1982): 171-188.

Carson, Richard G., Stephan Riek, and Nosratollah Shahbazpour. "Central and peripheral mediation of human force sensation following eccentric or concentric contractions." The Journal of physiology 539.3 (2002): 913-925. https://doi.org/10.1113/ jphysiol.2001.013385

Cullen, Kathleen E. "Sensory signals during active versus passive movement." Current opinion in neurobiology 14.6 (2004): 698-706. https:// doi.org/10.1016/j.conb.2004.10.002

De Vignemont, Frédérique. Mind the body: An exploration of bodily self-awareness. Oxford University Press, 2018.

-. "Body schema and body image - Pros and cons." Neuropsychologia 48.3 (2010): 669-680. https://jeannicod.ccsd.cnrs.fr/ijn_00512315

—. «Bodily spatial content.» Psyche 15.1 (2009).

Devitt, Michael. "Methodology and the nature of knowing how." The Journal of Philosophy 108.4 (2011): 205-218. https:/ / www.jstor.org/ stable/23039015

Goodwin, G. M., D. I. McCloskey, and P. B. Matthews. "The contribution of muscle afferents to kinesthesia shown by vibration induced illusions of movement and by the effects of paralysing joint afferents." Brain 95.4 (1972): 705-748. https://doi.org/10.1093/ brain/95.4.705 
Gregory, J. E., D. L. Morgan, and U. Proske. "Aftereffects in the responses of cat muscle spindles and errors of limb position sense in man." Journal of neurophysiology 59.4 (1988): 1220-1230. https:// doi.org/10.1152/jn.1988.59.4.1220

Grigg, Peter, Gerald A. Finerman, and Lee H. Riley. "Joint-position sense after total hip replacement." The Journal of Bone and Joint Surgery 55.5 (1973): 1016-1025.

Hurley, Susan L. Consciousness in action. Harvard University Press, 1998.

Jones, Lynette A. "Motor illusions: What do they reveal about proprioception?" Psychological bulletin 103.1 (1988): 72. https:/ / doi. org/10.1037/\%2F0033-2909.103.1.72

Jones, L. A., and I. W. Hunter. "Effect of fatigue on force sensation." Experimental neurology 81.3 (1983): 640-650. https:/ / doi. org/10.1016/0014-4886(83)90332-1

Jones, O. R. “Things Known without Observation." Proceedings of the Aristotelian Society 61 (1960): 129-150. https://www.jstor.org/ stable/ 4544644

Jones, Stephanie A., Erin K. Cressman, and Denise Y. Henriques. "Proprioceptive localization of the left and right hands." Experimental brain research 204.3 (2010): 373-383. https://doi.org/10.1007/ s00221-009-2079-8

Longo, Matthew R., and Patrick Haggard. "An implicit body representation underlying human position sense." Proceedings of the National Academy of Sciences 107.26 (2010): 11727-11732. https:/ / doi. org/10.1073/pnas.1003483107

Lotze, Rudolf Hermann. Microcosmus: An essay concerning man and his relation to the world [Mikrokosmus: Ideen zur Naturgeschichte und Geschichte der Menschheit, Versuch einer Anthropologie]. Trans. E. Hamilton and E. Jones. Vol. 1. Edinburgh: T \& T Clark, 1856.

Macefield, G., S. C. Gandevia, and D. Burke. "Perceptual responses to microstimulation of single afferents innervating joints, muscles and skin of the human hand." The Journal of Physiology 429.1 (1990): 
113-129. https:/ / dx.doi.org/10.1113\%2Fjphysiol.1990.sp018247

Mandrigin, Alisa. "The where of bodily awareness." Synthese, first online: 8 April 2019 (2019): 1-17. https://doi.org/10.1007/s11229019-02171-3

Margolis, Joseph. "Awareness of sensations and of the location of sensations." Analysis 27.1 (1966): 29-32. https://www.jstor.org/ stable/3326983

Martin, Michael. "Sense modalities and spatial properties." Spatial Representation. Ed. Naomi Eilan, Rosaleen Mc-Carthy, and Bill Brewer. Oxford: Basil Blackwell, 1993. 206-218.

McDowell, John. "Anscombe on bodily self-knowledge." Essays on Anscombe's Intention. Ed. Anton Ford, Jennifer Hornsby, and Frederick Stoutland. Harvard University Press, 2011. 129-146.

McIntyre, A. K. "Central actions of impulses in muscle afferent fibres." Muscle receptors. Ed. C. Hunt. Berlin, Heidelberg: Springer, 1974. 235-288.

Merleau-Ponty, Maurice. Phénoménologie de la Perception. Paris: Gallimard, 1945. [English translation: Phenomenology of Perception. Trans. Colin Smith. Routledge \& Kegan Paul, 1962]

Noë, Alva. Action in perception. Cambridge: MIT Press, 2004.

Noë, Alva, and Kevin O'Regan. "A sensorimotor account of vision and visual consciousness." Behavioral and Brain Sciences 24.5 (2001): 883-917.

O'Shaughnessy, Brian. "Proprioception and the Body Image." The Body and the Self. Ed. José Bermúdez, Anthony Marcel, and Naomi Eilan. Cambridge: MIT Press, 1995. 175-203.

-. The Will: A dual aspect theory. Vol. I. Cambridge: Cambridge University Press, 1980. 2 vols.

Pedersen, Jonas, et al. "Localized muscle fatigue decreases the acuity of the movement sense in the human shoulder." Medicine 
and Science in Sports and Exercise 31.7 (1999): 1047-1052. https:/ / doi. org/10.1097/00005768-199907000-00019

Penfield, Wilder, and Herbert Jasper. Epilepsy and the functional anatomy of the human brain. Oxford: Little, Brown \& Co., 1954.

Pickard,Hanna. "Knowledge of Action withoutObservation." Proceedings of the Aristotelian Society 104.1 (2004): 205-230.

Proske, Uwe, and Simon C. Gandevia. "The proprioceptive senses: their roles in signaling body shape, body position and movement, and muscle force." Physiological reviews 92.4 (2012): 1651-1697. https:// doi.org/10.1152/ physrev.00048.2011

Russell, Bertrand. The problems of philosophy. Oxford: Oxford University Press, 1912.

Schaefer, Michael, et al. "Fooling your feelings: Artificially induced referred sensations are linked to a modulation of the primary somatosensory cortex." Neuroimage 29.1 (2006): 67-73. https:// doi. org/10.1016/j.neuroimage.2005.07.001

Setiya, Kieran. “Practical knowledge.” Ethics 118.3 (2008): 388-409.

Sherrington, Charles S. "The muscular sense". Textbook of physiology 2 (1906): 1002-1025.

- . The integrative action of the nervous system. Cambridge: Cambridge University Press, 1906.

Velleman, J. David. Practical reflection. Princeton: Princeton University Press, 1989.

Vesey, Godfrey N. A. “The location of bodily sensations.” Mind 70.277 (1961): 25-35.

-. "Knowledge without observation." The Philosophical Review 72.2 (1963): 198-212.

-. "Bodily sensations." Australasian Journal of Philosophy 42.2 (1964): 232-247. https:// doi.org/10.1080/00048406412341201 
Weerakkody, NivanSargara, et al. “Force matching at the elbow joint is disturbed by muscle soreness." Somatosensory and Motor Research 20.1 (2003): 27-32. https:/ / doi.org/10.1080/0899022031000083816

Como citar:

Murillo Lara, Luis Alejandro. "Bodily sensations and the varieties of spatial bodily awareness." Discusiones Filosóficas. Jul. 21 (37), 2020: 15-35. https://doi.org/10.17151/difil.2020.21.37.2 